\title{
Marie-Hélène Grintchenko, Catherine de Bourbon (1559-1604). Influence politique, religieuse et culturelle d'une princesse calviniste
}

\section{Michele Mastroianni}

\section{(2) OpenEdition \\ Journals}

Edizione digitale

URL: http://journals.openedition.org/studifrancesi/6592

DOI: $10.4000 /$ studifrancesi.6592

ISSN: 2421-5856

\section{Editore}

Rosenberg \& Sellier

\section{Edizione cartacea}

Data di pubblicazione: 1 septembre 2010

Paginazione: 351-352

ISSN: 0039-2944

\section{Notizia bibliografica digitale}

Michele Mastroianni, «Marie-Hélène Grintchenko, Catherine de Bourbon (1559-1604). Influence politique, religieuse et culturelle d'une princesse calviniste», Studi Francesi [Online], 161 (LIV | II) | 2010, online dal 30 novembre 2015, consultato il 13 janvier 2021. URL: http://journals.openedition.org/studifrancesi/ 6592 ; DOI: https://doi.org/10.4000/studifrancesi.6592

Questo documento è stato generato automaticamente il 13 janvier 2021.

\section{cc) (†) $\odot$}

Studi Francesi è distribuita con Licenza Creative Commons Attribuzione - Non commerciale - Non opere derivate 4.0 Internazionale. 


\title{
Marie-Hélène Grintchenko, Catherine de Bourbon (1559-1604). Influence politique, religieuse et culturelle d'une princesse calviniste
}

\author{
Michele Mastroianni
}

\section{NOTIZIA}

MARIE-HÉLÈNE GRINTCHENKO, Catherine de Bourbon (1559-1604). Influence politique, religieuse et culturelle d'une princesse calviniste, Paris, Champion, 2009 («Vie des Huguenots», 50), pp. 1066.

1 Si sono moltiplicati, in un passato prossimo e nel presente, studi e convegni consacrati al governo delle donne, alle femmes d'état, nel Cinque e Seicento. Si pensi al proliferare di lavori, per l'area inglese, su Elisabetta I e su Maria Stuarda e, per l'area francese, su Caterina de Medici. Ora, la ponderosa thèse di M.-H. Grintchenko arricchisce il panorama del gouvernement des femmes con un nuovo personaggio, quello della sorella di Enrico IV, che senza dubbio esercitò un ruolo significativo durante le guerre di religione, in cui incarnò le esigenze della pars protestante in Francia. Fedele anzitutto al proprio clan, quello dei Bourbons, e alla politica del fratello, non sacrificò tuttavia, come fece quest'ultimo, alle esigenze politiche - neppure a quelle della pacificazione la propria fede riformata, che conservò e difese sul piano personale fino alla morte, evidenziando quel complesso gioco di strategie politiche e religiose, di equilibri che avranno una composizione nell'editto di Nantes, di dinamiche contraddittorie fra odî e passioni che trovano rispondenze anche in una produzione letteraria spesso fortemente schierata nell'apologia.

2 La prima parte del lavoro analizza le strutture sociali e i réseaux che si allacciano intorno a quella che fu l'ultima infanta di Navarra (pp. 25-378): anzitutto i legami di 
parentela, con tutti i problemi dinastici che ne provengono per questa casata di Bourbon-Vendôme che finirà con l'ereditare la corona di Francia; liens de parenté che sono al centro dell'attenzione politica, come attesta lo spazio che occupano nelle testimonianze epistolari, e che si complicano per le divisioni confessionali che attraversano lo stesso lignage. In secondo luogo, i legami concernenti il personale della maison de Madame. Come l'A. sottolinea, «le maisons principesche servivano da matrici culturali. Esse riunivano delle élites cortigiane che cercavano la protezione di un principe e la loro rete di influenza si estendeva, tanto a corte quanto in provincia, su una larghissima parte della società, sia nobile sia non aristocratica. La comunanza di interessi dei membri della maison e la condivisione quotidiana delle stesse esperienze sociali e culturali permettevano l'emergere di un gruppo di corte contraddistinto da un carattere particolare, fortemente influenzato dalla personalità del principe e il cui ascendente sulla società dipendeva dal prestigio di quest'ultimo» (p. 243). La seconda parte ripercorre l'evoluzione dell'influenza politica, finanziaria e religiosa di Catherine (pp. 381-741), esaminando le tre fasi successive della sua vita pubblica: la reggenza delle terre di Navarra, il soggiorno a corte, col rango di prima signora di Francia, tra il 1593 e il 1598, il periodo del matrimonio con il duca di Bar. Anche in questa sezione l'A. è particolarmente attenta a ricostruire i legami personali, e, soprattutto, ad analizzare le strategie politiche e l'intrecciarsi di interessi religiosi. Nella terza parte del volume si studia la produzione letteraria - religiosa, politica e di propaganda-concernente in qualche modo il personaggio (pp. 745-960): raccolte poetiche, controversie religiose, discorsi, opere satiriche e balletti di corte che diffondono intorno a Catherine una propaganda attiva. Non solo si tratta di testimonianze che illustrano «l'identità culturale e le polemiche contemporanee di cui è necessario valutare l'impatto sul corso della storia; ma di testi che evidenziano la percezione che i contemporanei avevano della personalità e del potere di Catherine, dei suoi doveri e dei suoi diritti. I poeti di corte dell'entourage reale e del partito ugonotto le indirizzano le loro opere, portatrici della simbolica tradizionalmente riferita alla 'persona' della principessa» (p. 21). Analisi, questa, interessante per il quadro che disegna dei rapporti tra letteratura e propaganda negli ultimi decenni del Cinquecento. 